\title{
The Quartercentenary Lecture
}

\section{Undernutrition and chronic disease: cancer}

\author{
BY DAVID KRITCHEVSKY \\ The Wistar Institute, 3601 Spruce Street, Philadelphia, PA 19104-4268, USA
}

\section{EARLY HISTORY: ANIMAL STUDIES}

About 60 years ago McCay et al. $(1935,1939)$ showed that limiting the food intake of rats increased their life span and reduced symptoms of degenerative disease. Almost 30 years earlier Moreschi (1909) found that growth of transplanted tumours was severely inhibited when the mice bearing those tumours were underfed. A few years later Rous (1914) reported that neither spontaneous nor transplanted tumours grew well in rodents whose energy intake was restricted. There was considerable interest in the effects of dietary restriction on tumour growth in the second and third decades of this century. The early findings have been reviewed by Kritchevsky \& Klurfeld (1986).

In the early 1940s two laboratories in the United States, those of Tannenbaum at the Michael Reese Hospital in Chicago and Baumann at the University of Wisconsin, began to investigate effects of diet on experimental tumourigenesis. Initially Tannenbaum (1940) found that underfeeding reduced the incidence of both spontaneous and chemically-induced tumours in mice. In underfeeding the same diet is fed to all the animals, some being allowed to feed freely and some being fed on a lower level of the same diet. The underfeeding is either designed to maintain the test animals at a predetermined weight or they are fed a proportion of the intake of the control group. Under conditions of underfeeding experiments, if the controls are ingesting the limiting amount of a necessary micronutrient the underfed group may become deficient in this nutrient with deleterious metabolic consequences. In the energy-restriction mode, the diets are designed to provide equal levels of vitamins and minerals and restriction is effected at the expense of a macronutrient. After his initial effort Tannenbaum (1942) formulated a diet of known energy content. Energy-restriction studies using this diet showed that incidence of spontaneous mammary or lung tumours or chemically-induced skin tumours was lowered significantly in several strains of mice (Tannenbaum, 1942). Incidence of spontaneous hepatomas was also affected by energy restriction (Tannenbaum \& Silverstone, 1949).

Tannenbaum (1945) also showed that at the same level of energy intake a diet high in fat led to a higher incidence of mammary tumours than did one low in fat. Boutwell et al. $(1949 a)$ confirmed this observation in mice bearing chemically-induced skin tumours. Energy restriction was most effective during the progression phase of tumourigenesis; restriction during initiation followed by ad lib. feeding yielded results similar to those seen when the mice were fed freely throughout the experiment (Tannenbaum, 1944).

Lavik \& Baumann (1943) studied dietary effects in mice treated with methylcholanthracene to produce skin tumours. The mice were fed on diets low in energy and low in fat (incidence $0 \%$ ); low in energy and high in fat (incidence 28\%); high in energy 
but low in fat (incidence 54\%); and high in both energy and fat (incidence 66\%). Albanes (1987a) reviewed eighty-two studies involving energy restriction and tumourigenesis in mice and a low-fat, high-energy regimen (eighteen studies) was $56 \%$ more carcinogenic than a high-fat, low energy regimen (nineteen studies). Interest in energy restriction and cancer waned after 1950 being eclipsed by studies of the co-carcinogenic effects of dietary fat but was revived in the 1980 s.

\section{RECENT ANIMAL STUDIES}

Kritchevsky et al. (1984) observed that $40 \%$ energy restriction completely inhibited the growth of 7,12-dimethyl-1,2-benz(a)anthracene (DMBA)-induced mammary tumours when the dietary fat was coconut oil (plus enough maize oil for essential fatty acid repletion). The energy-restricted rats were fed twice as much fat as the $a d$ lib.-fed controls. Boissonneault et al. (1986) administered DMBA to female rats fed on a high-fat diet (300 $\mathrm{g}$ maize oil $/ \mathrm{kg}$ ), a low-fat diet ( $50 \mathrm{~g}$ maize oil $/ \mathrm{kg}$ ) or the high-fat diet restricted by $18.5 \%$. Tumour incidence on the three diets was 73,43 and $7 \%$ respectively. The daily energy intakes of the three groups were 170,178 and $146 \mathrm{~kJ} / \mathrm{d}$. Klurfeld et al. (1987) showed that $40 \%$ energy restriction also inhibited 1,2-dimethylhydrazine (DMH)-induced tumours in rats. Rats fed on saturated fat exhibited a lower incidence of tumours than rats fed on an unsaturated fat confirming an earlier observation of Carroll \& Khor (1971).

In a study designed to determine the lowest degree of energy restriction required to inhibit DMBA-induced tumourigenesis Klurfeld et al. (1989a) restricted energy by 10, 20,30 or $40 \%$. All rats, including the controls, ingested $50 \mathrm{~g}$ fat $/ \mathrm{kg}$ diet daily. At $10 \%$ restriction tumour incidence was the same as that seen in the controls $(60 \%)$ but tumour multiplicity (tumours/tumour-bearing rat) was reduced by $32 \%$ and tumour burden (weight of all tumours/rat) was reduced by $47 \%$. Restriction of energy by $20 \%$ reduced tumour incidence to $40 \%$ but tumour multiplicity and tumour burden were similar to those seen in rats whose energy was restricted by $10 \%$. At $30 \%$ energy restriction tumour incidence, multiplicity and burden (compared with the controls) were reduced by 42,72 and $91 \%$ respectively. Only one of the twenty rats whose energy was restricted by $40 \%$ exhibited a tumour. Plasma insulin levels in the rats subjected to 30 or $40 \%$ restriction were significantly lower than those observed in the other groups.

To determine whether a diet high in fat (oil) could override energy restriction, groups of female rats were given DMBA and fed on either 50,150 , or $200 \mathrm{~g}$ fat $/ \mathrm{kg} a d \mathrm{lib}$. or 200 or $267 \mathrm{~g}$ fat $/ \mathrm{kg}$ with a $25 \%$ energy restriction (Klurfeld et al. 1989b). The two energyrestricted groups ingested exactly the same amount of fat daily as did the ad lib.-fed groups fed on 150 or $200 \mathrm{~g}$ fat $/ \mathrm{kg}$. In the ad lib.-fed groups tumour incidence in rats fed on 50,150 or $200 \mathrm{~g}$ fat $/ \mathrm{kg}$ was 65,85 and $80 \%$ respectively. Tumour multiplicity was 1.9 , 3.0 and 4.1 and tumour burden $4.2,6.6$ and $11.8 \mathrm{~g}$. Tumour incidence in the groups whose energy intake was restricted by $25 \%$ was $60 \%$ in rats fed on $200 \mathrm{~g}$ maize oil $/ \mathrm{kg}$ and $30 \%$ in those fed on $267 \mathrm{~g} \mathrm{fat} / \mathrm{kg}$. Tumour multiplicity in the two groups was 1.9 and 1.5 and tumour burden 1.5 and $2.3 \mathrm{~g}$. Plasma insulin levels in the two restricted groups were significantly lower than those in the control groups. Welsch et al. (1990) fed DMBAtreated rats on 50 or $200 \mathrm{~g}$ fat $/ \mathrm{kg}$ diets administered ad lib. or at $12 \%$ energy restriction. At $50 \mathrm{~g}$ fat $/ \mathrm{kg}$ energy restriction reduced tumour yield by $29 \%$ and at $200 \mathrm{~g}$ fat $/ \mathrm{kg}$ by $37 \%$. Rats fed on $200 \mathrm{~g}$ fat $/ \mathrm{kg}$ ad lib. exhibited $56 \%$ more tumours than those fed on $50 \mathrm{~g}$ $\mathrm{fat} / \mathrm{kg}$; at $12 \%$ energy restriction the difference was $38 \%$. The incidence of colon 
tumours induced by an indirect-acting carcinogen, methylazoxymethanol, is inhibited by energy restriction but tumours due to the action of $\mathrm{N}$-methylnitrosourea, a direct-acting carcinogen are unaffected (Pollard \& Luckert, 1985). This dichotomy merits further investigation.

The time in life at which energy restriction must be instituted to be effective was investigated by Tannenbaum (1947). The incidence of spontaneous breast tumours observed in 20-month-old DBA mice was zero when energy restriction was begun at 2 months. When restriction was begun at 5 or 9 months of age tumour incidence was reduced by 95 and $80 \%$ respectively. Weindruch \& Walford (1982) restricted energy intake of cancer-prone mice by $44 \%$ when they were 1 year old. Incidence of hepatomas was reduced by $7 \%$, lymphomas by $34 \%$, and lung tumours by $50 \%$. Life span of the mice bearing tumours was increased by $12 \%$ and that of the tumour-free mice was increased by $23 \%$. Kritchevsky et al. (1989) tested effects of intermittent energy restriction on DMBA-induced mammary tumours and found a relationship between increasing feed efficiency and increasing tumour incidence. Ross \& Bras (1973) and Ross et al. (1982) found that incidence of spontaneous tumours was increased by high feed efficiency and rapid growth. Ross \& Bras (1971) found that lifelong dietary energy restriction (by $60 \%$ ) of rats increased life span by about $40 \%$ and decreased incidence of spontaneous tumours by $90 \%$. When rats were restricted for 7 weeks after weaning then returned to an ad lib. regimen life expectancy was not increased but incidence of spontaneous tumours fell by almost $40 \%$.

\section{RELEVANCE TO MAN}

Hoffman (1913) urged the formation of a society to study cancer incidence in the United States and suggested that 'erroneous diet' was probably a factor in the aetiology of cancer. Hoffman (1927) later proposed that energy excess was an important factor in the cancer development. Berg (1975) also proposed that cancers prevalent in the United States might be related to high energy intake. Lew \& Garfinkel (1979) and Garfinkel (1985) have shown relationships between overweight and cancer mortality in a cohort of over one million people.

The epidemiology of breast cancer suggests that early onset of menarche increases risk of breast cancer in women (Staszewski, 1971). Tall stature may also be a risk factor (DeWaard, 1975). Both age at onset of menarche and stature are influenced by nutritional status (Apter \& Vihko, 1983). Swanson et al. (1988) assessed data from the first US National Health and Nutrition Examination Survey (NHANES I) and found that stature and frame size, but not body weight, were associated with increased risk of breast cancer in women. A prospective study of 23831 Norwegian women (Vatten \& Kvinnsland, 1990) found that women taller than $1.67 \mathrm{~m}$ displayed a greater risk for breast cancer than those shorter than $1.59 \mathrm{~m}$. The association appeared to be confined to women whose prepubertal growth occurred between 1940 and 1945. Kritchevsky (1990) summarized international data relating to body weight and risk of breast cancer in women. In all, eleven studies were examined and nine of them found a positive relationship between breast cancer risk and body weight or height or body mass index, BMI (weight/height ${ }^{2}$ ).

Albanes et al. (1988) correlated adult stature and cancer risk in men and women using data from NHANES I. They concluded that short stature was associated with reduced 
cancer risk, especially in men. There is a strong genetic component to their findings but nutrition may also play a role. Albanes \& Taylor (1990) examined the differences in height and weight with cancer incidence on an international scale. They found highly significant correlations between tumours at all sites and height for both women and men. Lindsted et al. (1991) found a significant negative trend between diminishing BMI and cancer risk in Seventh Day Adventist men. Albanes (1987b) reviewed the international data relating to energy intake, body weight and cancer. Increased body weight, high relative body weight or high energy intake were associated with increased risk of cancers of the breast, colon, rectum, prostate, endometrium, kidney, cervix, ovary, thyroid and gallbladder. There was an inverse correlation between cancers of the bladder, stomach and lung. Total energy intake has been shown to be related significantly to the incidence of colon (Jain et al. 1980; Lyon et al. 1987) or gastric (Graham et al. 1990) cancer.

\section{EXERCISE}

Increasing energy flux may be as effective as reducing energy intake. Rusch \& Kline (1944) subjected mice bearing a transplanted tumour to enforced exercise (cage rotation) and tumour weight was reduced by about $30 \%$. Vigorous treadmill exercise reduced incidence of DMH-induced colon tumours in rats by about $50 \%$. The incidence of colon tumours in ad lib.-fed, exercised rats was about the same as that observed in sedentary rats subjected to $25 \%$ energy restriction (Klurfeld et al. 1988). Cohen et al. (1988) reported that voluntary exercise (activity cage) reduced mammary tumours in rats and voluntary exercise has also been shown to inhibit pancreatic cancer (Roebuck et al. 1990). Exercise has also been shown to inhibit growth of Morris hepatoma 7777 in rats (Baracos, 1989). On the other hand, Thompson et al. $(1988,1989)$ found that treadmill exercise actually enhanced the growth of DMBA-induced mammary tumours in rats. Their exercised rats ate more food and weighed more than the sedentary controls. Vigorous occupational physical activity has been shown to reduce the risk of colon cancer in men (Garabrant et al. 1984; Vena et al. 1985; Gerhardsson et al. 1988). In this regard it is interesting to note that over 70 years ago Sivertsen \& Dahlstrom (1921) showed a relationship between energy expenditure and cancer risk; however, the group with lowest occupational activity and highest cancer death rate lived 10-15 years longer. Risk of cancer may also be reduced by regular exercise (Paffenbarger et al. 1987).

\section{MECHANISMS}

The mechanisms by which energy restriction affects carcinogenesis are moot. One probable reason for this is that the effects of energy restriction have not been regarded seriously. Other, more immediate effects on carcinogenesis have been studied in a reflection of the one disease, one cause, one cure paradigm.

Free radicals derived from oxygen have been implicated as possible factors in tumourigenesis and there has been much activity in the cancer field related to anticancer effects of antioxidant vitamins such as $\mathrm{A}, \mathrm{E}$ and $\mathrm{C}$ as well as of carotenoids. Rao et al. (1990) showed that energy restriction increased the activities of superoxide dismutase $(E C 1.15 .1 .1)$, catalase $(E C 1.11 .1 .6)$ and glutathione peroxidase $(E C 1.11 .1 .9)$ in livers of aging rats. Yu (1991) reported that the activities of superoxide anion, hydroxyl anion and hydrogen peroxide fell by 27,28 and $6 \%$ respectively in the livers of energyrestricted rats. 
Boutwell et al. (1949b) suggested that energy restriction of female rats resulted in 'pseudohypophysectomy' reducing the size of the ovaries and uterus. They also observed adrenal hypertrophy. Energy restriction has been shown to reduce levels of circulating mammotrophic hormones in rats and mice (Sylvester et al. 1981, 1982; Sarkar et al. 1982).

Energy restriction in mice, whether instituted early or late, prolongs life, reduces lympho-proliferative disease, stimulates immunological responses and increases the interleuken-2 productive capacity of lymph nodes but not spleen cells (Kubo et al. 1984).

The influences of energy restriction on aspects of DNA metabolism are positive in the direction of cancer control. Energy restriction leads to enhanced DNA repair (Lipman et al. 1989) and reverses to a degree the age-related loss of specific activity and fidelity of DNA-polymerases (Srivastava et al. 1991). Energy restriction increases formation of DNA adducts called I compounds (Randerath et al. 1991). Oncogene expression in rats (Fernandes et al. 1987) and mice (Nakamura et al. 1989) is reduced by energy restriction. Himeno et al. (1992) find that energy restriction inhibits expression of $c$-fos and $c-k i$-ras mRNA in mice.

Koizumi et al. (1992) studied body temperature in two strains of mouse whose weekly energy intake was reduced by $49 \%$. Energy restriction extended life span drastically in both male and female mice and reduced spontaneous tumourigenesis by $55 \%$ in the males and by $96 \%$ in the females. Mitotic activities in the intestine of energy-restricted female mice housed at $20-22^{\circ}$ were reduced by $73 \%$ but when the mice were housed at $30^{\circ}$ the mitotic index was only $21 \%$ lower. The authors concluded that the severe reduction in mitotic activity is due to energy restriction-induced torpor.

Insulin deprivation will inhibit tumour growth and cell division (Cohen \& Hilf, 1974; Taub et al. 1987). When tumour-bearing rats are made diabetic the tumours stop growing (Heuson \& Legros, 1972). Plasma insulin levels fall significantly in rats subjected to energy restriction (Klurfeld et al. 1989a,b). Insulin levels fall immediately upon institution of energy restriction in rats and remain low throughout the restricted regimen. The levels of insulin-like growth factor I (IGF-I) also fall at first but rebound to normal within a few weeks; levels of IGF-II are unaffected (Ruggeri et al. 1989). Both IGF-I and II have been shown to stimulate the growth of human breast cancer cells in culture (Osborne et al. 1990). Aging results in a slight decrease in plasma IGF-I concentrations in rats and the decrease is accelerated significantly in energy-restricted animals. Aging also results in reduction of IGF-I mRNA and this reduction is prevented by dietary restriction (Breese et al. 1991). In mice both insulin receptor and glucocorticoid receptor mRNA increase with age. The latter is not influenced by dietary restriction but the former is increased about $20 \%$ in $52 \%$ energy-restricted mice (Spindler et al. 1991). Hepatic insulin receptors are also increased in energy-restricted rats (Balage et al. 1988) and binding of insulin to rat liver nuclei is increased by food restiction (Venkatraman \& Fernandes, 1992). How these events affect tumour growth is unclear.

Holehan \& Merry (1986) published an extensive review of dietary manipulation of aging. Many of the mechanisms discussed in detail by them are applicable to the present presentation.

\section{CONCLUSION}

In conclusion it seems abundantly evident that reduction of energy intake and, to a lesser degree, increased energy output inhibit tumourigenesis (spontaneous, induced or 
transplanted) in rodents. A modest reduction in energy intake appears to be a simple and inexpensive approach to reduction of cancer risk in man.

\section{REFERENCES}

Albanes, D. (1987a). Total calories, body weight and tumor incidence in mice. Cancer Research 47, 1987-1992. Albanes, D. (1987b). Caloric intake, body weight and cancer: A review. Nutrition and Cancer 9, 199-217.

Albanes, D., Jones, D. Y., Schatzkin, A., Micozzi, M. S. \& Taylor, P. R. (1988). Adult stature and risk of cancer. Cancer Research 48, 1658-1662.

Albanes, D. \& Taylor, P. R. (1990). International differences in body height and weight and their relationship to cancer incidence. Nutrition and Cancer 14, 69-77.

Apter, D. \& Vihko, R. (1983). Early menarche, a risk factor for breast cancer, indicates early onset of ovulatory cycles. Journal of Clinical Endocrinology and Metabolism 57, 82-86.

Balage, M., Manin, M., Arnal, M. \& Grizard, J. (1988). Differential regulation of muscle and liver insulin receptors by energy restriction in growing rats. Reproductive Nutrition Development 18, 819-820.

Baracos, V. E. (1989). Exercise inhibits progressive growth of the Morris hepatoma 7777 in male and female rats. Canadian Journal of Physiology and Pharmacology 67, 864-870.

Berg, J. W. (1975). Can nutrition explain the pattern of international epidemiology of hormone-dependent cancer? Cancer Research 35, 3345-3350.

Boissonneault, G. A., Elson, C. E. \& Pariza, M. W. (1986). Net energy effects of dietary fat on chemically induced mammary carcinogenesis in F344 rats. Journal of the National Cancer Institute \% 6, 335-338.

Boutwell, R. K., Brush, M. K. \& Rusch, H. P. (1949a). The stimulating effect of dietary fat on carcinogenesis. Cancer Research 9, 741-746.

Boutwell, R. K., Brush, M. K. \& Rusch, H. P. (1949b). Some physiological effects associated with chronic caloric restriction. American Journal of Physiology 154, 517-524.

Breese, C. R., Ingram, R. L. \& Sonntag, W. E. (1991). Influence of age and long-term dietary restriction on plasma insulin-like growth factor-1 (IGF I), IGF I gene expression, and IGF I binding proteins. Journal of Gerontology 46, B180-187.

Carroll, K. K. \& Khor, H. T. (1971). Effect of level and type of dietary fat on incidence of mammary tumors induced in female Sprague-Dawley rats by 7,12-dimethylbenz(a)anthracene. Lipids 6, 415-420.

Cohen, L. A., Choi, K. \& Wang, C.-X. (1988). Influence of dietary fat, caloric restriction and voluntary exercise on N-nitrosomethylurea-induced mammary tumorigenesis in rats. Cancer Research 48, 4276-4283.

Cohen, N. D. \& Hilf, R. (1974). Influence of insulin on growth and metabolism of 7,12-dimethylbenz(a)anthracene-induced mammary tumors. Cancer Research 34, 3245-3252.

DeWaard, F. (1975). Breast cancer incidence and nutritional status with particular reference to body weight and height. Cancer Research 35, 3351-3356.

Fernandes, G., Khare, A., Langamere, S., Yu, B., Sandberg, L. \& Fredricks, B. (1987). Effect of food restriction and aging on immune cell fatty acids, functions and oncogene expression in SPF Fischer 344 rats. Federation Proceedings 46, 567.

Garabrant, D. H., Peters, J. M., Mack, T. M. \& Bernstein, L. (1984). Job activity and colon cancer risk. American Journal of Epidemiology 119, 1005-1014.

Garfinkel, L. (1985). Overweight and cancer. Annals of Internal Medicine 103, 1034-1036.

Gerhardsson, M., Floderus, B. \& Norell, S. E. (1988). Physical activity and colon cancer risk. International Journal of Epidemiology 17, 743-746.

Graham, S., Haughey, B. \& Marshall, J. (1990). Diet in the epidemiology of gastric cancer. Nutrition and Cancer 13, 19-34.

Heuson, J. C. \& Legros, N. (1972). Influence of insulin deprivation on growth of the 7,12-dimethylbenz(a)anthracene-induced mammary carcinoma in rats subjected to alloxan diabetes and food restriction. Cancer Research 32, 226-232.

Himeno, Y., Engelman, R. W. \& Good, R. W. (1992). Influence of calorie restriction on oncogene expression and DNA synthesis during liver regeneration. Proceedings of the National Academy of Sciences, USA 89, $5497-5501$.

Hoffman, F. L. (1913). The menace of cancer. American Journal of Obstetrics and Diseases of Women and Children 68, 88-91.

Hoffman, F. L. (1927). Cancer Increase and Overnutrition. Newark, New Jersey: Prudential Insurance Co. 
Holehan, A. M. \& Merry, B. J. (1986). The experimental manipulation of ageing by diet. Biological Reviews 61, 329-368.

Jain, M., Cook, G. M., Davis, F. G., Grace, M. G., Howe, G. R. \& Miller, A. B. (1980). A case-control study of diet and colorectal cancer. International Journal of Cancer 26, 757-768.

Klurfeld, D. M., Weber, M. M. \& Kritchevsky, D. (1987). Inhibition of chemically-induced mammary and colon tumor promotion by caloric restriction in rats fed increased dietary fat. Cancer Research $\mathbf{4 7}$, 2759-2762.

Klurfeld, D. M., Welch, C. B., Davis, M. J. \& Kritchevsky, D. (1989a). Determination of degree of energy restriction necessary to reduce DMBA-induced mammary tumorigenesis in rats during the promotion phase. Journal of Nutrition 119, 286-291.

Klurfeld, D. M., Welch, C. B., Einhorn, E. \& Kritchevsky, D. (1988). Inhibition of colon tumour promotion by caloric restriction or exercise in rats. FASEB Journal 2, A433.

Klurfeld, D. M., Welch, C. B., Lloyd, L. M. \& Kritchevsky, D. (1989b). Inhibition of DMBA-induced mammary tumorigenesis by caloric restriction in rats fed high fat diets. International Journal of Cancer $\mathbf{4 3}$, 922-925.

Koizumi, A., Tsukada, M., Wada, Y., Masuda, H. \& Weindruch, R. (1992). Mitotic activity in mice is suppressed by energy restriction-induced torpor. Journal of Nutrition 122, 1446-1453.

Kritchevsky, D. (1990). Nutrition and breast cancer. Cancer 66, 1321-1325.

Kritchevsky, D. \& Klurfeld, D. M. (1986). Influence of caloric intake on experimental carcinogenesis: A review. Advances in Experimental Medicine and Biology 206, 55-68.

Kritchevsky, D., Weber, M. M. \& Klurfeld, D. M. (1984). Dietary fat versus caloric content in initiation and promotion of 7,12-dimethylbenz(a)anthracene-induced mammary tumorigenesis in rats. Cancer Research 44, 3174-3177.

Kritchevsky, D., Welch, C. B. \& Klurfeld, D. M. (1989). Response of mammary tumors to caloric restriction for different time periods during the promotion phase. Nutrition and Cancer 12, 259-269.

Kubo, C., Day, N. K. \& Good, R. A. (1984). Influence of early or late dietary restriction on life span and immunological parameters in MRL/Mp-Ipr/lpr mice. Proceedings of the National Academy of Sciences, USA 81, 5831-5835.

Lavik, P. S. \& Baumann, C. A. (1943). Further studies on the tumor-promoting action of fat. Cancer Research 3, 749-756.

Lew, E. A. \& Garfinkel, L. (1979). Variations in mortality by weight among 750,000 men and women. Journal of Chronic Diseases 32, 563-576.

Lindsted, K., Tonstad, S. \& Kuzma, J. W. (1991). Body mass index and patterns of mortality among Seventh-Day Adventist men. International Journal of Obesity 15, 397-406.

Lipman, J. M., Turturro, A. \& Hart, R. W. (1989). The influence of dietary restriction on DNA repair in rodents: A preliminary study. Mechanisms of Ageing and Development 48, 135-143.

Lyon, J. L., Mahoney, A. W., West, D. W., Gardner, J. W., Smith, K. R., Sorensen, A. W. \& Stanish, W. (1987). Energy intake: Its relation to colon cancer. Journal of the National Cancer Institute 78, 853-861.

McCay, C. M., Crowell, M. F. \& Maynard, L. A. (1935). The effect of retarded growth upon the length of life span and upon the ultimate body size. Journal of Nutrition 10, 63-79.

McCay, C. M., Ellis, G. H., Barnes, L. J., Smith, C. A. H. \& Sperling, G. (1939). Chemical and pathological changes in aging and after retarded growth. Journal of Nutrition 18, 15-25.

Moreschi, C. (1909). Beziehungen zwischen Ernährung und Tumorwachstum. Zeitschrift für Immunitätsforsch 2, 651-675.

Nakamura, K. D., Duffy, P. H., Lu, M.-S., Turturro, A. \& Hart, R. W. (1989). The effect of dietary restriction on myc protooncogene expression in mice: A preliminary study. Mechanisms of Ageing and Development 48, 199-205.

Osborne, C. K., Clemmons, D. R. \& Arteaga, C. L. (1990). Regulation of breast cancer growth by insulin-like growth factors. Journal of Steroid Biochemistry and Molecular Biology 37, 805-809.

Paffenbarger, R. S. Jr, Hyde, R. T. \& Wing, A. L. (1987). Physical activity and incidence of cancer in diverse populations: A preliminary report. American Journal of Clinical Nutrition 45, 312-317.

Pollard, M. \& Luckert, P. H. (1985). Tumorigenic effects of direct and indirect-acting chemical carcinogens in rats on a restricted diet. Journal of the National Cancer Institute 74, 1347-1349.

Randerath, E., Hart, R. W., Turturro, A., Danna, T. F., Reddy, R. \& Randerath, K. (1991). Effects of aging and caloric restriction on I-compounds in liver, kidney and white blood cell DNA of male brown-Norway rats. Mechanisms of Ageing and Development 58, 279-296. 
Rao, G., Xia, E., Nadakavukaren, M. J. \& Richardson, A. (1990). Effect of dietary restriction on the age-dependent changes in the expression of antioxidant enzymes in rat liver. Journal of Nutrition 120, $602-609$.

Roebuck, B. D., McCaffrey, J. \& Baumgartner, K. J. (1990). Protective effects of voluntary exercise during the postinitiation phase of pancreatic carcinogenesis in the rat. Cancer Research 50, 6811-6816.

Ross, M. H. \& Bras, G. (1971). Lasting influence of early caloric restriction on prevalence of neoplasms in the rat. Journal of the National Cancer Institute 47, 1095-1113.

Ross, M. H. \& Bras, G. (1973). Influence of protein under- and overnutrition on spontaneous tumor prevalence in the rat. Journal of Nutrition 103, 944-963.

Ross, M. H., Lustbader, E. D. \& Bras, G. (1982). Dietary practices of early life and spontaneous tumors of the rat. Nutrition and Cancer 3, 150-167.

Rous, P. (1914). The influence of diet on transplanted and spontaneous tumors. Journal of Experimental Medicine 20, 433-451.

Ruggeri, B. A., Klurfeld, D. M., Kritchevsky, D. \& Furlanetto, R. W. (1989). Caloric restriction and 7,12-dimethylbenz(a)anthracene-induced mammary tumor growth in rats: Alterations in circulating insulin, insulin-like growth factors I and II, and epidermal growth factor. Cancer Research 49, 4130-4134.

Rusch, H. P. \& Kline, B. E. (1944). The effect of exercise on the growth of a mouse tumor. Cancer Research 4, 116-118.

Sarkar, N. H., Fernandes, G., Telang, N. T., Kourides, I. A. \& Good, R. A. (1982). Low calorie diet prevents the development of mammary tumors in $\mathrm{C} 3 \mathrm{H}$ mice and reduces circulating prolactin level, mammary tumor virus expression, and proliferation of mammary alveolar cells. Proceedings of the National Academy of Sciences, USA 79, 7758-7762.

Sivertsen, I. \& Dahlstrom, A. W. (1921). The relation of muscular activity to carcinoma. A preliminary report. American Journal of Cancer 6, 365-377.

Spindler, S. R., Grizzle, J. M., Walford, R. L. \& Mote, P. L. (1991). Aging and restriction of dietary calories increases insulin receptor $\mathrm{mRNA}$, and aging increases glucocorticoid receptor $\mathrm{mRNA}$ in the liver of female C3B10RF mice. Journal of Gerontology 46, B233-237.

Srivastava, V. K., Tilley, R. D., Hart, R. W. \& Busbee, D. L. (1991). Effect of dietary restriction on the fidelity of DNA polymerases in aging mice. Experimental Gerontology 26, 453-466.

Staszewski, J. (1971). Age at menarche and breast cancer. Journal of the National Cancer Institute 47, 935-940.

Swanson, C. A., Jones, D. Y., Schatzkin, A., Brinton, L. A. \& Ziegler, R. G. (1988). Breast cancer risk assessed by anthropometry in the NHANES I epidemiological follow-up study. Cancer Research 48, $5363-5367$.

Sylvester, P. W., Aylsworth, C. F. \& Meites, J. (1981). Relationship of hormones to inhibition of mammary tumor development by underfeeding during the 'critical period' after carcinogen administration. Cancer Research 41, 1383-1388.

Sylvester, P. W., Aylsworth, C. F., van Vogt, D. A. \& Meites, J. (1982). Influence of underfeeding during the "critical period' or thereafter on carcinogen-induced mammary tumors in rats. Cancer Research $\mathbf{4 2}$, $4943-4947$.

Tannenbaum, A. (1940). The initiation and growth of tumors. Introduction. I.' Effects of undernutrition. American Journal of Cancer 38, 335-350.

Tannenbaum, A. (1942). The genesis and growth of tumors. II. Effects of calorie restriction per se. Cancer Research 2, 460-467.

Tannenbaum. A. (1944). The dependence of the genesis of induced skin tumors on the caloric intake during different stages of carcinogenesis. Cancer Research 4, 673-677.

Tannenbaum, A. (1945). The dependence of tumor formation on the composition of the calorie-restricted diet as well as on the degree of restriction. Cancer Research 5, 616-625.

Tannenbaum, A. (1947). Effects of varying caloric intake upon tumor incidence and tumor growth. Annals of the New York Academy of Science 49, 5-17.

Tannenbaum, A. \& Silverstone, H. (1949). The influence of the degree of caloric restriction on the formation of skin tumors and hepatomas in mice. Cancer Research 9, 724-727.

Taub, R., Roy, A., Dieter, R. \& Koontz, J. (1987). Insulin as a growth factor in rat hepatoma cells. Journal of Biological Chemistry 262, 10893-10897.

Thompson, H. J., Ronan, A. M., Ritacco, K. A. \& Tagliaferro, A. R. (1989). Effect of type and amount of dietary fat on the enhancement of rat mammary tumorigenesis by exercise. Cancer Research 49, $1904-1908$.

Thompson, H. J., Ronan, A. M., Ritacco, K. A., Tagliaferro, A. R. \& Meeker, L. D. (1988). Effect of exercise on the induction of mammary carcinogenesis. Cancer Research 48, 2720-2723. 
Vatten, L. J. \& Kvinnsland, S. (1990). Body height and risk of breast cancer: A prospective study of 23,831 Norwegian women. British Journal of Cancer 61, 881-885.

Vena, J. E., Graham, D., Zielezny, M., Swanson, M. K., Barnes, R. E. \& Nolan, J. (1985). Lifetime occupational exercise and colon cancer. American Journal of Epidemiology 122, 357-365.

Venkatraman, J. \& Fernandes, G. (1992). Modulation of age-related alterations in membrane composition and receptor-associated immune functions by food restriction in Fischer 344 rats. Mechanisms of Ageing and Development 63, 27-44.

Weindruch, R. \& Walford, R. L. (1982). Dietary restriction in mice beginning at 1 year of age: Effect on life span and spontaneous cancer incidence. Science 215, 1415-1418.

Welsch, C. W., House, J. W., Herr, B. L., Eliasberg, S. J. \& Welsch, M. A. (1990). Enhancement of mammary carcinogenesis by high levels of dietary fat: A phenomenon dependent on ad libitum feeding. Journal of the National Cancer Institute 82, 1615-1620.

Yu, B. P. (1991). Free radicals and modulation by dietary restriction. Age and Nutrition 2, 84-88. 